\title{
DIE KOLONISASIE VAN AFRIKA
}

Afrika in die oudheid.

Anders as Amerika en Asië, wat geografies verder verwyder was van die middelpunt van die Wes-Europese beskawing, het die Afrikaanse kontinent eers laat in die moderne tyd die voorwerp van belangstelling van Europa geword. Die grootste deel van Afrika, hoewel dit direk aan Europa en Asië grens, het tot diep in die 19de eeu terra incognita gebly. In die oudheid het die begrip Afrika slegs die Nylvallei en die noordelike kusstrook van die kontinent gedek. Met die verowering van Egipte en die besetting van Noord-Afrika deur die Romeine, het daardie gebied feitlik deel van Europa geword. Die Middellandse See het 'n Romeinse binne-see (mare nostrum) geword.

Noord-Afrika gedurende die Middeleeue 'n weswaartse verlengstuk van Asië.

Die opkoms van die Mohammedanisme teen die einde van die 6de eeu n.C. het gelei tot die onderwerping van die Noord-Afrikaanse kus vanaf Egipte tot Tanger aan die Arabiese Ryk wat aanvanklik vanuit Bagdad (Damaskus) bestuur is, later Kairo en Kordoba (Spanje). Aan die einde van die Middeleeue het die Ottomaanse Turke (ook Mohammedane) hierdie ryk ingelyf en sedertdien was Egipte, Libië, Tripolitanië, Tunisië, Algerië, en Morokko provinsies van die Turkse Ryk met erkenning van die soewereiniteit (susereiniteit) van die Sultan (Kalief) in Konstantinopel. Dit was Keiserryk en Pousdom in een persoon verenig. Hierdie toestand het voortgeduur tot die 19de eeu, toe die Ottomaanse Ryk meer en meer tekens van aftakeling vertoon en die afgeleë provinsies in Noord-Afrika vrywel onafhanklik van die gesag van Konstantinopel geword het. Die res van Afrika is intussen dwarsdeur die eeue tot diep in die moderne tyd omhul deur 'n heidense duisternis so swart soos die velle van sy inheemse bewoners.

Die uitbreiding van Europa vanaf die moderne tyd het ooswaarts en weswaarts gegaan, nie suidwaarts deur Afrika nie.

Die groot rede waarom die binneland van Afrika vir soveel eeue onbekend gebly het, was sy klimaat en geografiese omstandighede. Die ontsaglike woestyn-barriere het die deurgang suidwaarts vanaf die Middellandse See doeltreffend versper. Die oerwoude aan die sentrale 
weskus en die bos- en koorsstreke aan die ooskus sowel as die bergreekse wat parallel met die ooskus loop, het onoorkomelike hindernisse geblyk te wees. Maar heeltemal afgesien daarvan het die binneland van Afrika suid van die Sahara geen ekonomiese aantreklikheid soos die speserye van die Ooste en die edel metale van die Weste gehad nie. Selfs die toenemende bekendstelling van die Afrikaanse kus in 'n suidelike rigting vanaf die $15 \mathrm{de}$ eeu het hierin geen verandering gebring nie. Die eienaardige toestand het dus sedert die begin van die moderne tyd ontstaan dat die maritieme volkere van Wes-Europa hulle oë na die verre Ooste en die Nuwe Wêreld in die weste gerig het, hoewel die suidpunt van Afrika deur Diaz omseil is nog voordat Columbus sy tog oor die westelike oseaan begin het. Afrika het onbekend gebly.

Portugese ontdekkingsreise.

Was daar nog hoop dat die deel van Afrika wat aan die Middellandse See geleë is, weer soos in die tyd van Rome 'n Europese invloedsfeer kon word, dan is daardie hoop die nek ingeslaan deur die Portugese ontdekking van die seeweg na Indië. Die politieke en kommersiële hegemonie van Genua en Venesië het daardeur verlore gegaan, want die wêreldhandel het van die Middellandse See na die oop oseane verskuif. Dit was ook 'n politieke magsverskuiwing na die maritieme volke van Wes-Europa.

Die vestiging van Portugese gesag in die verre Ooste en die gereelde Portugese seevaart om die kus van Afrika het egter nie gelei tot die opening van die Afrikaanse binneland nie. Die kennis van die seevaarders na die Ooste het feitlik beperk gebly tot die kuslyn waar eensame padraos gedien het as simbole van die Christelike beskawing. Weens die roete wat die Portugese gevolg het, was hulle seemanne verplig om die kus van Wes-Afrika (Angola) en Oos-Afrika (Mosambiek) aan te doen, en hulle gesag daar het beperk gebly tot enkele fortifikasies langs die kus. Driehonderd jaar later was dit nog die geval, want Portugal se oë was altyd op die eindpunt, Indië, gerig. Die forte langs die pad was slegs aanleg- en verversingsposte. Eers gedurende die afgelope honderd jaar het Portugal sy Afrikaanse besittinge tot kolonies ontwikkel.

Die Hollandse belangstelling in Suid-Afrika.

Die Hollandse mededinging met die Portugese in die Verre Ooste het aan die einde van die 16 de eeu 'n aanvang geneem, en voor die einde van die eerste helfte van die 17 de eeu het hulle daarin geslaag om die Portugese uit die Molukke en Speseryeilande te verdryf. Daar het 
hulle 'n eie handelsryk gevestig, en hulle anwesigheid aan die suidpunt van Afrika is daardeur bepaal. Hulle besondere roete, gerig op die Sundastraat, het hulle met die Afrikaanse kontinent in aanraking gebring en slegs op sy uiterste suidpunt. Maar die verversingstasie aldaar het onwillekeurig en teen die sin van die Direkteur van die N.O.I.K. tot blanke kolonisasie gelei. Die uiteindelike resultaat is bekend: die Unie van Suid-Afrika. Kolonisasie van suidelike Afrika deur Boere en Engelse het vir baie jare gestuit op onwil en teenstand van sowel die Nederlandse as die Britse gesagvoerders in Europa. In elk geval is die weg van Britse kolonisasie in suidelike Afrika moontlik gemaak deur die Boere wat byna oral die pioniers was.

\section{Die Slawehandel.}

Nieteenstaande die Portugese en Hollandse nedersettings langs die Wes-Ooskus en die suidpunt respektiewelik het Europese belangstelling in Afrika suid van die Sahara beperk gebly tot die voordele van die slawehandel, hoofsaaklik aan die Weskus, en wel vir 'n tydperk wat byna ' $n$ eeu en 'n half geduur het, vanaf 1650 tot 1800 . Die Engelse handelaars het hier die voortou geneem, gevolg deur die Franse, Portugese, Hollanders, Dene en ander Westerse volkere. Die Engelse alleen het vroeg in die $18 \mathrm{de}$ eeu sowat 25,000 slawe jaarliks na die Nuwe Wêreld uitgevoer, veral as gevolg van die Asiento wat hulle in 1713 van Spanje verkry het. Voor die einde van die $18 \mathrm{de}$ eeu het die omvang van die handel jaarliks sowat 100,000 negers beloop. Bristol en Liverpool het hulle kommersiële welvaart hoofsaaklik daaraan te danke gehad. Die negers van Wes-Afrika is aan die Wes-Indiese planters en aan die Spaanse besittinge in die Nuwe Wêreld verkoop. ('n Soortgelyke handel is sedert baie eeue deur die Arabiere gedryf aan die Afrikaanse ooskus). Die slawehandel het wel die vestiging van faktorye en sterkpunte langs die kus meegebring, maar nooit die uitoefening van Europese gesag in die hinterland nie. Inteendeel, juis die pogings om die handel te onderdruk, het gelei tot kolonisasie deur Brittanje in Wes- sowel as in Oos-Afrika in die tweede helfte van die 19de eeu.

As gevolg van die slawehandel met die Nuwe Wêreld is "Afrika" beskou as die oostelike grens van die Atlantiese Oseaan net soos sy ooskus die westelike grens van die Indiese Oseaan was. Daartussen was niemandsland geleë. Die handel in slawe is aan die begin van die 19de eeu onwettig verklaar, maar dit is nog lank deur die Arabiere en Negers bedryf en slawerny as sodanig is nog nie uitgeroei nie. 
Die Ontdekking van die binneland van Afrika gedurende die 19de eeu.

Die werklike ontdekking van Afrika het gevolg lank nadat die Wes-Europese volkere hulle invloed en gesag in die Amerikas en die Verre Ooste, wat veel verder verwyder was, gevestig het. In hierdie taak het die Engelse 'n groot aandeel gehad, en dit het uiteindelik meegebring dat hulle die grootste voorsprong in die kolonisasie van die nuwe gebiede verkry het. Livingstone se reise is in hierdie opsig belangrik wat betref die opening van Afrika suid van die ewenaar:

1849: Livingstone deurkruis die Kalahari van suid na noord en besoek die Ngamimeer.

1852-56: Livingstone deurkruis Afrika van wes na oos en ontdek die Victoria-waterval.

1859, Livingstone ontdek die Nyassameer.

1868: Livingstone ontdek die Bangweolomeer.

Verder belangrik was:

1848: Rebmann bereik Kilimanjaro.

1849: Krapf bereik berg Kenya.

1850 - 1855: Barth bereis middel Nigergebied ens.

1857: Burton en Speke ontdek meer Tanganyika.

1858: Speke ontdek Victoria Nyanza.

1862: Speke en Grant bereik die bron van die Wit-Nyl by meer Victoria.

1864: Baker ontdek Albert Nyanza.

1877: Stanley volg die loop van die Kongo weswaarts tot by sy monding.

Die Wedloop om kolonies in Afrika.

Die ontdekking van Sentraal-Afrika tussen die Sahara in die noorde en die Kalahari in die suide was die voorspel tot 'n intense wedloop tussen die Westerse volkere om koloniale besit in daardie gebied te verwerf. Die laaste kwart van die 19de eeu was 'n tydperk van oplewende imperialisme, wat nie slegs die verhoging van die politieke prestige van die Europese moederlande beoog het nie, maar vera] ook gebaseer was op die begeerte om grondstowwe te verkry met die oog op die toenemende nywerheidswedywer tussen veral Engeland, Duitsland en Frankryk. Aan hierdie wedywer het ook deelgeneem Italië en Spanje, en selfs België het sy eise laat geld. Die belange van die inboorlingvolke is nie in ag geneem nie, en selfs die ou onafhanklike gebiede in Noord- en in Suid-Afrika het die speelbal van die nasies geword. 
Behalwe Portugal, wat nog steeds vasgeklou het aan sy Wes- en Oosafrikaanse besittinge en die hinterland wat hy in die $19 \mathrm{de}$ eeu geleidelik onder beheer gebring en Engeland, wat die suidpunt van Afrika in 1814 om strategiese redes in besit gehou het, was Frankryk die eerste moondheid wat 'n houvas op die kontinent verkry het, en wel Algerië in 1831. Frankryk het 'n uitweg gesoek vir sy nasionale aspirasies wat met die val van Napoleon in 1815 gefnuik is. $\mathrm{Na}$ die tweede nederlaag teen Duitsland in 1871 het hy andermaal (1881) op Afrika toegesak en Tunisië ingepalm. Met Algerië en Tunisië as basis, het Frankryk teen die einde van die eeu en die begin van die $19 \mathrm{de}$ eeu sy invloedsfeer oor die Sahara tot in Sentraal-Afrika uitgebrei en, nadat sy protektoraat oor Morokko deur die moondhede, na skerp diplomatieke teenstand van Duitsland, erken is, van dear ooswaarts totdat hy eindelik die grootste koloniale moondheid in Afrika was met Frans Noord-Afrika, Frans Wes-Afrika, en Frans Ekwatoriaal-Afrika. Sy enigste mededinger was Spanje, wat 'n klein kusstrook van Morokko langs die Noordweskus ingepalm het, terwyl die gebied om Tanger, regoor Gibraltar, geïnternasionaliseer is. Frankryk se opmars deur die Sahara met die uiteindelike doel om aan te sluit by die Franse nedersettings in Wes-Afrika was 'n noodsaaklike uitvloeisel van sy besetting van Algerië. Frankryk se inmenging in Noord-Afrika het onvermydelik gelei tot politieke botsing met sowel Italië as Duitsland, terwyl sy poging om deur te dring tot die Soedan tot 'n ernstige konflik met Engeland aanleiding gegee het. Aldus het koloniale ekspansie wrywing in Europa self veroorsaak.

In Egipte het Frankryk groot invloed uitgeoefen deur die feit dat die Suezkanaal (voltooi in 1869) 'n Franse onderneming was. Maar die Franse is daar deur Engeland (Disraeli) uitoorlê toe laasgenoemde die Khedief se beherende aandele in die Kanaal-maatskappy oorgeneem het (1875). Teen 1880 was Engeland diep geinteresseerd in Egipte ter wille van sy posisie in die Oostelike Middellandse See en in Indië, net soos Frankryk in Algerië en Italjë in Tunisië. In 1881 het Frankryk op aanhitsing van Bismarck, wat sy teenstanders se aandag wou aftrek van revanche oor Elsas-Lotaringe, 'n protektoraat oor Tunisië afgekondig tot verbittering van Italië, wat dit as sy invloedsfeer beskou het. In elk geval het hierdie daad Italië vir baie jare in die DuitsOostenrykse kamp geja.

In Egipte is Franse ambisies egter nie verwesenlik nie. Soos Frankryk vir Italië voorgespring het, is hy op sy beurt uitoorlê deur 
Engeland - albei lande het identiese belange gehad wat betref beheer oor die kanaalgebied. Met die oog op die slegte finansiële toestand van Egipte het Engeland en Frankryk 'n gesamentlike finansiële kontrole uitgeoefen en dit later uitgebrei na politieke kontrole. In 1881 het die Egiptenare in opstand gekom onder Arabi Pasha en toe Frankryk geweier het om gewapend op te tree, het Engeland alleen tussenbei gekom en die Khedief op sy troon herstel. Hierna het Engeland vryspel geniet, en hoewel Gladstone belowe het om Britse troepe te onttrek sodra sake normaal word, het dit nooit gebeur nie. Aldus het Engeland politieke en militêre beheer oor Egipte verkry sonder om dit so te bedoel "in a fit of absence of mind". Die vyandskap wat Engeland hom op die hals gehaal het van die kant van Frankryk is ten toppunt gevoer met die Fashoda-insident, toe die Franse in 1898 verhinder is om hulle aan die boloop van die $\mathrm{Nyl}$ in die Soedan te vestig, en eers in 1904 besleg toe die twee lande 'n Entente Cordiale gesluit het wat Egipte en die Soedan as Britse en Morokko en WesAfrika as Franse invloedsfeer afgebaken het.

Inmiddels het Italië met jaloerse oë die uitbreiding van Franse mag en invloed in Noord-Afrika wargeneem en in 1911 die Turkse gebied, wat ooswaarts tussen Tunisië en Egipte geleë was, na 'n kortstondige oorlog as Tripolitanië van die siek man van die Bosporus afgeneem. Langs die Rooi See het Italië sy nasionale aspirasies probeer bevredig deur die anneksasie van Eritrea en Somaliland en in 1896 selfs tevergeefs probeer om Abessinië te onderwerp. Hierdie doel is eers in 1936 deur Mussolini bereik, maar reeds in 1941 is die Italianers met geweld deur Britse magte daaruit gedryf.

Waar Brittanje in Noord-Afrika en die Soedan in 'n groot diplomatieke stryd met Frankryk gewikkel was wat hulle verhoudinge vir baie jare vertroebel het, moes hy ook die hoof bied aan Duitse mededinging in Wes- en Oos-Afrika. Duitsland, wat in 1871 verenig is, was aanvanklik nie geïnteresseerd in koloniale uitbreiding nie. Bismarck se groot oogmerk was om sy skepping in Europa te beveilig teen enige Franse poging om sy verlore gebied te herwin. Maar die besit van kolonies is teen die laaste kwart van die $19 \mathrm{de}$ eeu beskou as politiekekonomies belangrik, veral vir die opkomende industrie-lande. Die Duitse koloniale vereniging het hom veral daarvoor beywer totdat Bismarck geswig het voor die aanhoudende propaganda. Die Duitse nasionale prestige moes verhoog word deur koloniale wedywering met 
sy groot buurstate hoewel Duitsland op daardie stadium geen vloot besit het om sy oorsese handel te beskerm nie.

In April 1884 is 'n protektoraat afgekondig oor Suidwes-Afrika. In Julie 1884 is die kus van die Kameroengebied sowel as Togoland geannekseer. Gedurende 1884-85 is ook Tanganyika by die Duitse koloniale gebied gevoeg. Op daardie wyse het Duitsland miljoene vierkante myle grondgebied in Afrika verwerf sonder 'n leër of 'n vloot daarvoor te gebruik, geheel in teenstelling met die koloniale metodes van Engeland en Frankryk wat uitsluitlik op militêre mag gebaseer was.

Duitse gebiedsaanwins in Wes- en Oos-Afrika het gedien as verdere stimulus tot Britse imperialisme wat, gelei deur Rhodes, die grootste deel van Suid- en Sentraal-Afrika ingepalm het in die jare tussen 1884 en 1902, afgesien van Nigerië en die Goudkus in WesAfrika.

Om die prent te voltooi het ook die kleine België op die toneel verskyn. Leopold II van België het die ontdekkingsreisiger Stanley gefinansieer om ekspedisies in die Kongogebied te onderneem. Die resultaat was verdrae met inboprlinghoofde en die totstandkoming van die Kongostaat (1878 - 1884). Tegnies was die Kongo-Vereniging 'n internasionale kommersiële onderneming, maar weens Franse en Portugese bedenkinge is ' $n$ konferensie van Groot Moondhede in Berlyn gehou (1884-85). Die uitkoms was die Akte van Berlyn wat onderteken is deur die moondhede en waardeur die Kongo-bekken aan die Vereniging oorhandig is as die Kongo Vrystaat. Leopold was die persoonlike regeerder van die gebied, en die gewetenlose vors het spoedig die Berlynse bepalings insake vryhandel en internasionale kontrole in die wind geslaan. Sy bewind was korrupt en tiranniek, maar die koning het in sy doel geslaag om die gebied onder beheer van België te bring en die ander moondhede uit te sluit.

Teen 1914 was die ganse kontinent met uitsondering van Abessinië en die Negerstaat Liberië aldus onder die groot moondhede verdeel, en wel sonder te blik of te bloos en sonder om die wense of belange van die inboorlinge in ag te neem. Die geskiedenis van blanke kolonisasie in Afrika is inderdaad nie verheffend nie. Engeland het die Boere in Suid-Afrika en die Franse oor Egipte verkul. Frankryk het Italië oor Tunisië uitoorlê, en Duitsland het Engeland oor Suidwes-Afrika en die Kameroen voorgespring. Leopold van België het die hele Europa om die bos gelei, en hulle almal saam het die inheemse volkere van 
Afrika op koelbloedige wyse die slagoffers van imperialistiese magstrewe gemaak.

Die bevryding van Afrika.

Met die Eerste Wêreldoorlog, die toetrede van die Verenigde State van Amerika tot die konsert van nasies en die stigting van die Volkerebond, het daar groot kentering in die openbare mening t.o.v. kolonies gekom.

Die tydvak volgende op die Eerste en veral die Tweede Wêreldoorlog het die geleidelike uitskakeling van Europese invloed uit Afrika gesien. Eers het Duitsland as koloniserende moondheid deur die verdrag van Versailles (1919) padgegee en sy voormalige besit is formeel onder beheer van die Volkerebond geplaas. ' $n$ Nuwe beginsel is daarmee toegepas. In plaas van die ou protektoraatsbeginsel het gekom die Mandaatstelsel. In praktyk het Tanganyika, Suidwes-Afrika en 'n deel van Togoland onder Britse beheer gekom, die res van Togoland en die Kameroens onder Franse beheer en selfs België het sy aandeel in Ruanda-Urundi, grensende aan die Kongogebied, ontvang.

Na die Tweede Wêreldoorlog is ook Italië vrywel uitgeskakel toe Tripolitanië onafhanklik geword het, Somaliland 'n Trustgebied van die V.V.O. en Eritrea by Abessinië ingelyf is.

'Engeland en Frankryk het die vernaamste Europese moondhede in Afrika gebly, maar hulle het byna onmiddellik na 1945 kennis moes makk met 'n ontwakende nasionale gevoel onder die volkere van Afrika. Die gety het tussen die jare 1945 en 1955 haas onkeerbaar geword. Dit het gelei tot die volle onafhanklikheid van Egipte, Libië, Tunisië, en Morokko en die gedeeltelike ontvoogding van die Goudkus en Nigerië, met alle vooruitsigte vir die verdere verdwyning van Engeland en Frankryk behalwe uit die agterlikste en ekonomies swakste gebiede.

Afrika tussen Asië en Europa.

-. Die bevryde volkere van Afrika eis die bevryding van die res van die gebied van Europese politieke beheer. Terselfdertyd eis hulle 'n plek in die ry van volkere. Sowel Indië as China en die Sowjet-Unie beloof politieke en ekonomiese hulp in hierdie proses in die hoop dat Afrika die kant van die Ooste sal kies. Engeland, Frankryk, Portugal en die V.S.A. voer daarteenoor groot planne in die skild om Afrika op te hef en te ontwikkel. Die besef dring deur dat Afrika die enigste 
landmassa is wat die Weste teen die komende Oosterse offensief kan stel, dat Afrika die grootste bolwerk van die Westerse verdedigingsbastion teen die Kommunisme is. Internasionaal is Afrika tans oneindig belangriker vir Europa as voorheen, want dit is nie meer bloot 'n middel om 'n einddoel te bereik nie, maar belangrik op sigself.

D. W. KRUGGER.

P.U. vir C.H.O. 


\section{LITERATUURLYS}

Batten, T. R.: Tropical Africa in World History.

Coupland, R.: East Africa and its Invaders.

Coupland, R.: The Exploitation of East Africa, 1856-1890.

Crowe, S. E.: The Berlin West African Conference, 1884- 85

De Kock, W. J.: Die Portugese Ontdekkers aan ons Kuste.

Fvans, I. F.: The British in Tropical Africa.

Grant and Temperley: Europe in the 18th and 20th Centuries.

Inghan, K.: Europe and Africa.

Johnston, Sir Harry: A History of the Colonization of Africa by Alien Races.

Johnston, Sir Harry: The Opening-up of West Africa.

Kelth, B.: The Belgian Congo and the Berlin Act.

Keitle, Sir John Scott: The Partition of Africa.

Knight, M. M.: Morocco as a French Economic Venture.

Lewln, E.: The Germans and Africa.

Lovell, R. I.: The Struggle for South Africa.

Lucas, C. P.: The Partition and Colonization of Africa.

Lugard, F.: The Rise of our Empirc in East Africa

Lugard, F.: The Dual Mandate in British Tropical Africa.

Mooul, I'. T.: Imperialism and World Politics,

Muir, R.: The Expansion of Europe.

Reusch, R.: History of East Africa.

Rudin, H. R.: Germans in the Cameroons, 1884--85: A case study in modern imperialism.

Parry, J. H.: Europe and a Wider World.

Prestage, S.: Portuguese Pioneers. 